\author{
Jan BUREK ${ }^{1}$ \\ Joanna LISOWICZ ${ }^{2}$ \\ Tomasz RYDZAK ${ }^{3}$ \\ Artur SZAJNA ${ }^{4}$
}

\title{
PROGRAMOWANIE CYKLU PRZECHWYTU PRZEDMIOTU WRAZ Z JEGO ODCIECIEM DLA CENTRUM OBRÓBKOWEGO
}

\begin{abstract}
Przedstawiono opracowany w Katedrze Technik Wytwarzania i Automatyzacji Politechniki Rzeszowskiej cykl przechwytu z odcięciem przedmiotu dla centrum obróbkowego STAMA MC 726 MT, wykorzystując możliwości układu sterowania numerycznego SINUMERIK 840D produkcji SIEMENS. Wykorzystanie stworzonego cyklu pozwala na obróbkę przedmiotów w dwóch położeniach zaciskowych. Dodatkowo ułatwia redagowanie programu sterującego, a także zmniejsza jego rozmiar. W rozdziale pierwszym przedstawiono kinematykę osi sterujących obrabiarki CNC wraz z ich nazewnictwem oraz zakresem ruchu, na której zaimplementowano cykl. W rozdziale drugim omówiono funkcje i tryby pracy przewidziane przez producenta maszyny, wspomagające programowanie procesów obróbkowych oraz zdefiniowane specjalne zmienne globalne ułatwiające tworzenie kodu NC. W kolejnej części przedstawiono podział cykli w układzie sterowania SINUMERIK oraz działanie stworzonego cyklu, opisując jego fragmenty. Oprócz podstawowych kodów zastosowano zmienne: lokalne, globalne oraz systemowe, tworząc warunki skoków.
\end{abstract}

Słowa kluczowe: programowanie wysokopoziomowe, programowanie parametryczne, SINUMERIK 840D, obrabiarka wieloosiowa

\section{Wprowadzenie}

Wprowadzane do przemysłu coraz to nowsze i bardziej uniwersalne centra obróbkowe sterowane CNC umożliwiają obróbkę przedmiotów o skomplikowanej geometrii $\mathrm{w}$ jednym cyklu roboczym, $\mathrm{z}$ użyciem wielu narzędzi oraz podajników półfabrykatów, co umożliwia produkcję seryjną.

1 Jan Burek, Politechnika Rzeszowska, e-mail: jburek@prz.edu.pl

2 Joanna Lisowicz, Politechnika Rzeszowska, e-mail: j.lisowicz@ prz.edu.pl

3 Autor do korespondencji/corresponding author: Tomasz Rydzak, Politechnika Rzeszowska, ul. W. Pola 2, 35-959 Rzeszów, tel.: 17865 1131, e-mail: t.rydzak@prz.edu.pl

${ }^{4}$ Artur Szajna, Politechnika Rzeszowska, e-mail: a.szajna@prz.edu.pl 
Obserwuje się również ciągłą ewolucję układów sterowania obrabiarek - od prostego regulatora, aż do złożonego systemu sterowania umożliwiającego w trakcie pracy pełną automatyzację produkcji. Przykładem takiego centrum obróbkowego jest centrum frezarsko-tokarskie MC 726/MT firmy STAMA [7]. Centrum to jest obrabiarką posiadającą rozbudowaną kinematykę, umożliwiającą kompletną obróbkę części o skomplikowanej geometrii w jednym cyklu roboczym. Maszyna posiada wrzeciono frezarskie oraz dwa wrzeciona tokarskie pozwalające na toczenie z przechwytem przedmiotu. Dzięki temu istnieje możliwość obróbki przedmiotów w sześciu płaszczyznach, w dwóch położeniach zaciskowych.

Przestrzeń robocza obrabiarki ograniczona przez zakresy osi $\mathrm{X}, \mathrm{Y}, \mathrm{Z}$, wynoszące odpowiednio $500 \mathrm{~mm}, 380 \mathrm{~mm}, 360 \mathrm{~mm}$, pozwala na wykonanie przedmiotów małogabarytowych [3]. Układ kinematyki i nazewnictwo osi w centrum obróbkowym STAMA jest zgodne z normą DIN 66217. Możliwe jest sterowanie osi liniowych X, Y, Z, X' (XGR) oraz osi obrotowych A, B, AA, BB [2]. Maszyna posiada zautomatyzowany podajnik prętów, który pozwala na ciągłą obróbkę przedmiotów bez ustalania manualnego półfabrykatów, co ogranicza ingerencję operatora $\mathrm{w}$ proces skrawania. Podajnik i równocześnie magazyn prętów ułatwia wdrożenie seryjnej produkcji, redukując nakłady finansowe oraz czas produkcji [1].

\section{Funkcje i tryby pracy przewidziane przez producenta firmy STAMA wspomagające tworzenie programów obróbkowych}

Producent obrabiarki STAMA przewidział, w zależności od potrzeby obróbki, sześć funkcji przełączenia pomiędzy trybami pracy frezowania i toczenia:

- TURNRES (MILL) - operacje frezarskie,

- TURNV - toczenie $\mathrm{z}$ wrzeciona tokarskiego głównego w położeniu pionowym,

- TURNH - toczenie z wrzeciona głównego tokarskiego w położeniu poziomym,

- TURNV2 - toczenie z wrzeciona pomocniczego tokarskiego w położeniu pionowym,

- TURNH2 - toczenie z wrzeciona tokarskiego pomocniczego w położeniu poziomym,

- TURNV3 - toczenie $\mathrm{z}$ wrzeciona pomocniczego w położeniu pionowym z obróconym układem osi [1].

Funkcje MILL, TURNH(), TURNV() polegają na zmianie układu osi programowych pomiędzy frezowaniem a toczeniem, w zależności od obróbki. W przypadku funkcji MILL wrzeciono pionowe jest traktowane jako główne (programowe), natomiast pozostałe wrzeciona (tokarskie i przeciwwrzeciona) traktuje się jako osie obrotowe A oraz AA. W przypadku wyboru funkcji TURNH() lub TURNV() wrzeciono tokarskie jest wrzecionem głównym [3]. 
W układzie sterowania SIEMENS obrabiarki STAMA producent zdefiniował plik SMDATEN zawierający podstawowe parametry określające pozycje charakterystycznych punktów w przestrzeni obrabiarki. Informacje w nim zawarte są wywoływane w cyklach (standardowych, użytkownika, producenta). Parametrom tym zostały przypisane wartości zdefiniowane jako globalne dane użytkownika. Przykładowo GSM_BASPA jest to zmienna opisująca odległość od osi obrotu elementu poprzecznego do krawędzi uchwytu zaciskowego [3].

\section{Nowy cykl do przechwytu przedmiotu obrabianego wraz z odcięciem}

Cykle obróbkowe są to podprogramy technologiczne, za pomocą których realizuje się określone procesy obróbki [4]. W układzie sterowania SINUMERIK 840D cykle obróbkowe można podzielić na trzy grupy: cykle standardowe, użytkownika oraz producenta.

- Cykle standardowe - są to podprogramy sparametryzowane, opracowane przez producenta układu sterowania. Ich zadaniem jest wspomaganie programowania wykonywanych najczęściej zabiegów, np. toczenia zgrubnego/wykańczającego, wiercenia, frezowania kieszeni itp. [5]. Cykle te wywołuje się przez podanie nazwy oraz zmiennych zdefiniowanych przez użytkownika [4].

- Cykle użytkownika - są to podprogramy sparametryzowane przez użytkownika. Gdy zdefiniowane cykle standardowe są niewystarczające lub nieujęte dla danego zabiegu, istnieje możliwość stworzenia własnych cykli, przeznaczonych na dodatkowe zabiegi technologiczne [5].

- Cykle producenta - są to cykle stworzone przez producenta obrabiarki. Konieczność tworzenia cykli producenta zachodzi ze względu na sposób przeprowadzania technologii obróbki i specyfiki danej maszyny CNC. W większości przypadków cykle te są tworzone przez producenta obrabiarki [5].

W celu wykorzystania całego potencjału maszyny do wytwarzania przedmiotów w jednym cyklu roboczym, konieczna jest możliwość zmiany położenia obrabianego przedmiotu w przestrzeni roboczej obrabiarki. Aby móc to osiągnąć, ruch ten zaprogramowano za pomocą cyklu, ułatwiając tym samym redagowanie programu sterującego oraz zminimalizowanie jego rozmiarów. Ponadto przy synchronicznej pracy obu wrzecion, przy przechwycie, do cyklu opracowano dodatkową procedurę odcięcia przedmiotu w zależności od wyboru narzędzia do tego przeznaczonego, np. przecinakiem lub frezem, jeżeli zachodzi taka konieczność.

W układzie sterowania opisano i wprowadzono podprogram pod nazwą CYCLEV1, zapisany jako cykl użytkownika. Do stworzenia takiego cyklu wykorzystano zmienne systemowe oraz zdefiniowane przez producenta parametry, do których są przypisane wartości zlokalizowane w GUD8 (Globalne Dane 
Użytkownika). Przed przystąpieniem do tworzenia cyklu opracowano uproszczony flow chart, opisujący procedurę działania cyklu i służący do opracowania programu (rys. 1).

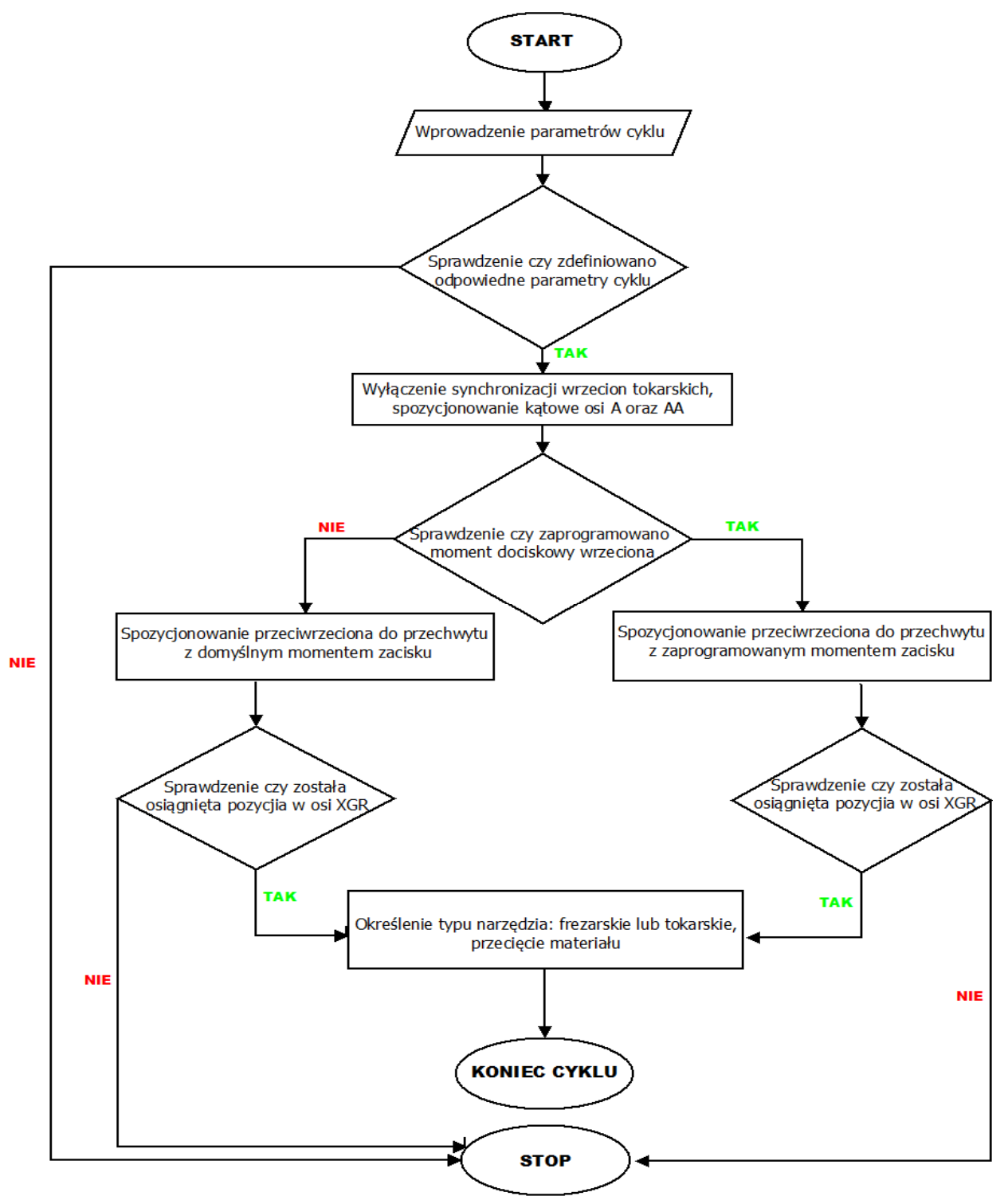

Rys. 1. Uproszczona procedura opisująca działanie cyklu

Fig. 1. A simplified procedure describing how the cycle works 
W pierwszej kolejności zdefiniowano rodzaje, nazwy i kolejność parametrów cyklu. Na rysunku 2 zobrazowano znaczenie niektórych zmiennych. Jako komentarze w programie opisano znaczenie poszczególnych parametrów.

PROC CYCLEV1(REAL_UR_ODL, REAL_UR_ZAC, REAL_UR_FFF, REAL_UR_APO, REAL UR_AAPO, INT _UR_MOM, REAL _UR_SREDNICA, REAL _UR_DLUGOSC, REAL _UR_R103, REAL_UR_R104) SAVE

;_UR_ODL - długość wysuniętego pręta do przestrzeni obróbkowej,

;_UR_ZAC - miejsce zacisku w osi XGR odnoszące się względem punktu bazowego przedmiotu zlokalizowanego na splanowanej powierzchni czołowej półfabrykatu,

;_UR_FFF - posuw dla dojazdu na pozycję_UR_ZAC,

;_UR_APO - spozycjonowanie osi A do zacisku,

;UR_AAPO - spozycjonowanie osi AA do zacisku,

;_UR_MOM - moment docisku przeciwwrzeciona,

;_UR_SREDNICA - średnica wałka do przecięcia,

;_UR_DLUGOSC - pozycja w osi X przecięcia przedmiotu obrabianego liczona od punktu bazowego przedmiotu,

;_UR_R103 - posuw zdefiniowany dla przecinania w zależności od wyboru narzędzia,

;_UR_R104 - prędkość wrzeciona w przypadku przecinania za pomocą freza/stała prędkość skrawania w przypadku przecinania za pomocą przecinaka

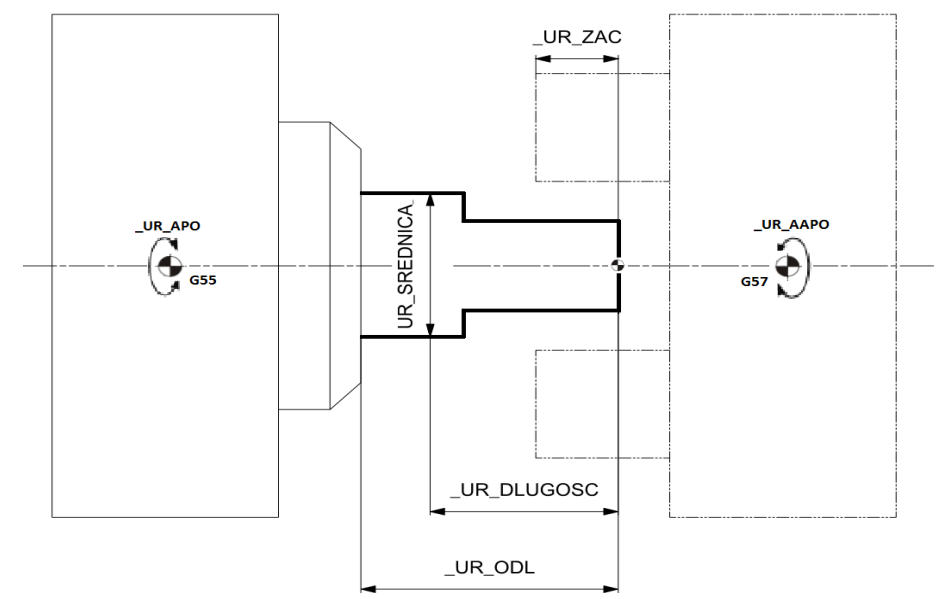

Rys. 2. Graficzne przedstawienie zmiennych cyklu

Fig. 2. Graphical representation of cycle variables

Następnie zdefiniowano parametry bezpośrednie i pośrednie. Wartość całkowita parametru ZACISK służy do sprawdzenia osiągniętej żądanej pozycji w osi XGR. Parametr MOMENT jest wykorzystywany w przypadku, gdy nie został zdefiniowany parametr_UR_MOM. Parametry _UR_WT1 oraz _UR_WT2 określają numery wrzecion odpowiednio: tokarskiego i przeciwwrzeciona. TR0 służy do określenia odległości od wysuniętego czoła pręta do G55.

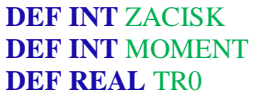


DEF REAL UR VAR 1, UR VAR 2

DEF REAL UR WT1 $=2$, UR WT2 $=3$

TR0=GSM_BASPA+_UR_ODL; MOMENT $=30$

Za pomocą zmiennej systemowej \$P_SUBPAR sprawdza się, czy zostały zaprogramowane odpowiednie parametry cyklu. W przypadku braku parametru na interfejsie sterownika wyświetla się komunikat $\mathrm{z}$ informacją przedefiniowania cyklu. W zabezpieczeniu dalszej próby kontynuacji pracy programu następuje przeskok do bloku PEND, gdzie jest zdefiniowany koniec programu za pomocą M30.

IF $(($ \$P_SUBPAR $[1]<>$ TRUE) OR (\$P_SUBPAR $[2]<>$ TRUE $)))$

MSG("PARAMETRY CYKLU MUSZA BYC ZDEFINIOWANE")

M0

GOTOF PEND

ENDIF

IF (\$P_SUBPAR[3]<>TRUE)

UR FFF $=400$

ENDIF

IF ((\$P_SUBPAR[7]<>TRUE) OR (\$P_SUBPAR[8]<>TRUE) OR (\$P_SUBPAR[9]<>TRUE) OR (\$P_SUBPAR[10]<>TRUE)))

MSG("PARAMETRY CYKLU MUSZA BYC ZDEFIONIOWANE")

M0

GOTOF PEND

ENDIF

W kolejnym kroku zdefiniowano zmienną, która określa pozycje najazdu przeciwwrzeciona poprzez zmienne globalne i zdefiniowaną wcześniej zmienną lokalną.

_UR_VAR_1=-(GSSPOS_X - GSM_XDREMI - GSSBOBKA - TR0)

W drugiej kolejności sprawdza się, czy wrzeciona tokarskie są ze sobą sprzężone. Jeżeli tak, to następuje wyłączenie pracy synchronicznej wrzecion.

IF \$AA_EG_ACTIVE[SPI(_UR_WT1),SPI(_UR_WT2)]==TRUE

SYNCOF

ENDIF

Przez zmienną systemową \$AC_SMODE zostaje sprawdzony tryb pracy wrzeciona. Jeżeli nie jest w trybie pracy osi, następuje (ruchem G0) pozycjonowanie kątowe. Z kolei M70 przełącza wrzeciono $2 \mathrm{w}$ tryb pracy jako oś [6].

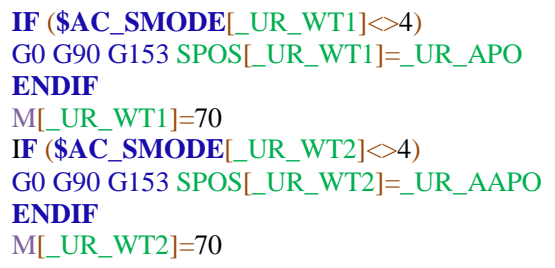

Następnie jest sprawdzane, czy osie B oraz BB są ze sobą sprzężone. Jeżeli tak, to następuje wyłączenie pracy synchronicznej osi przez SYNCOF. 
IF \$AA_EG_ACTIVE $[\mathrm{B}, \mathrm{BB}]==$ TRUE

SYNCOF

ENDIF

W kolejnym kroku spozycjonowano osie B i BB na pozycje kątowe przez zmienne GSSUEPOS_B oraz GSSUEPOS_BB, które są zdefiniowane w pliku producenta SMDATEN.

G0 G90 G153 B=GSSUEPOS_B BB=GSSUEPOS_BB

Przez M54 następuje blokada osi, z wyłączeniem osi XGR (M568). Następnie jest zaprogramowany dojazd przeciwwrzeciona na pozycję $20 \mathrm{~mm}$ od czoła półfabrykatu.

M54 M568 ;G0 G90 G153 XGR=_UR_VAR_1 +_UR_ZAC + 20

Ze względu na wartość momentu zacisku przeciwwrzeciona wprowadzono warunek momentu zacisku. Jeśli zaprogramowany moment zacisku jest mniejszy niż 30, to wykonywana jest następująca instrukcja:

IF (_UR_MOM<30)

Ruchem G1 wykonuje się przejazd przeciwwrzeciona na pozycję zacisku przedmiotu obrabianego z zaprogramowanym posuwem. Skuteczny moment zacisku zostaje zredukowany do $30 \%$ przez FXST[]. Następuje włączenie monitorowania kontroli osiągnięcia pozycji zacisku za pomocą funkcji FXS[] w osi XGR. Jeżeli nie została osiągnięta pozycja zacisku, następuje wycofanie przeciwwrzeciona oraz wyświetlenie komunikatu na interfejsie sterownika. Poprzez M547 następuje zacisk uchwytu.

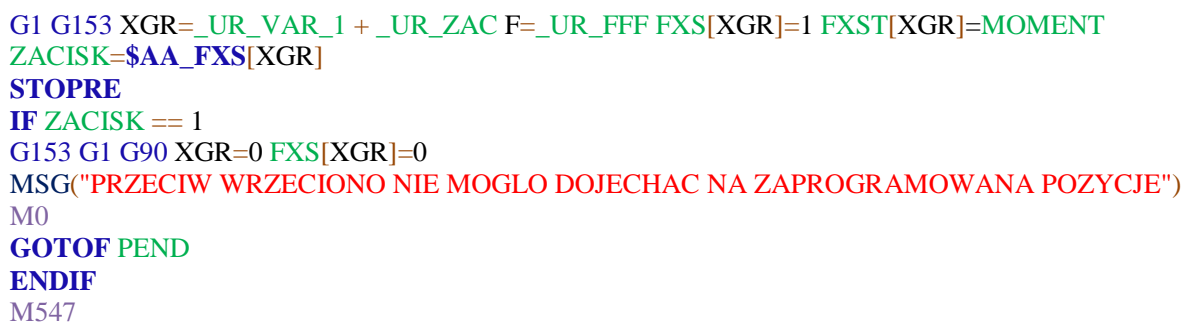

W kolejnym kroku jest wykonana instrukcja programowa przecinania detalu ze względu na typ narzędzia. W tej części programu przez zmienną systemową \$TC_DP1 sprawdza się, czy wywołane narzędzie (\$P_TOOLNO) zdefiniowane do przecięcia jest typu tokarskiego.

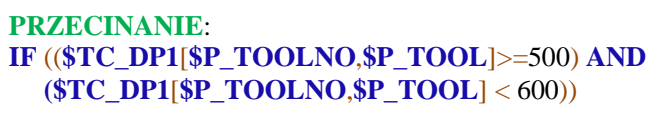

Dalej załączany jest tryb toczenia poziomego TURNH, który transformuje układ współrzędnych trzech osi na odpowiednie dla toczenia dwie osie. Wywołano układ współrzędnych G55 wraz z jego przesunięciem na powierzchnię 
czołową wysuniętego półfabrykatu przez TRANS. Załączono pracę synchroniczną osi A oraz AA przez SYNCON.

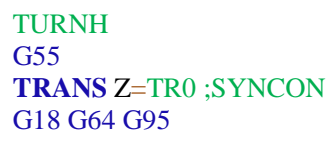

W kolejnym etapie następuje spozycjonowanie narzędzia oraz przecięcie obrabianego przedmiotu z określonym posuwem oraz stałą prędkością skrawania. Po wykonaniu przecięcia następuje odjazd na bezpieczną odległość.

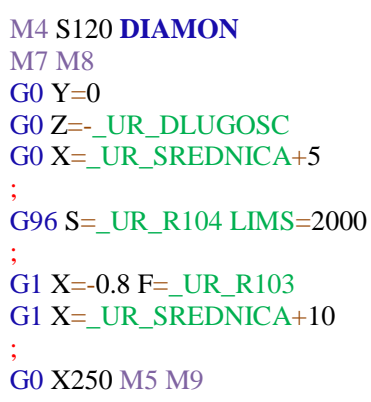

Po wykonaniu przecięcia praca synchroniczna zostaje wyłączona, następuje odwołanie transformacji oraz wyłączenie programowania średnicowego.

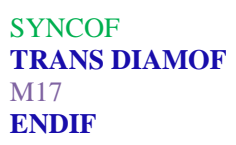

W przypadku gdy narzędzie nie jest typu tokarskiego, sprawdza się kolejny warunek. Należy sprawdzić, czy wywołane narzędzie, zdefiniowane do przecięcia przedmiotu obrabianego, jest typu frezarskiego.

IF ( $\$$ TC_DP1[\$P_TOOLNO, \$P_TOOL] $>=120)$ AND

(\$TC_DP1[\$P_TOOLNO,\$P_TOOL] $<200)$ )

W dalszej kolejności jest wyłączana praca synchroniczna obu wrzecion. Zostaje załączony tryb frezowania MILL i wywołany układ współrzędnych G55 wraz z jego przesunięciem na powierzchnię czołową wysuniętego półfabrykatu przez TRANS.

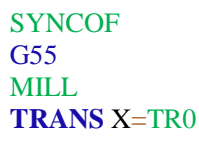

Określono płaszczyznę obróbki G17, posuw dla frezowania G94 oraz stały posuw w punkcie odniesienia ostrza narzędzia przez CFTCP [6]. 
Następuje określenie prędkości obrotowej wrzeciona przez zdefiniowaną zmienną _UR_R104, załączenie obrotów oraz włączenie chłodziwa.

\section{S=_UR_R104 M3 M8}

Następnie pozycjonuje się narzędzie frezarskie. \$TC_DP6 jest zmienną systemową określającą promień narzędzia frezarskiego. Posuw został określony parametrem_UR_R103.

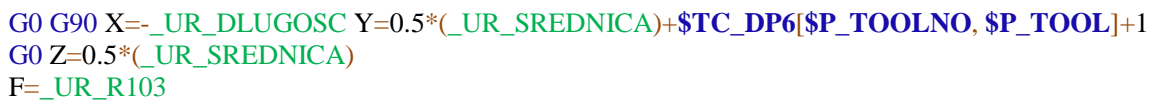

Dalej została opisana struktura fragmentu programu, która jest sparametryzowana, co oznacza, że czynności wykonywane w trakcie obróbki zależą od wcześniej zdefiniowanych parametrów. Następnie określono przejazdy przez warunki skoków. Frezowanie jest powtarzane, aż do osiągnięcia odpowiednich wartości zdefiniowanych warunkami ,if”. Jeżeli warunek nie jest spełniony, program wraca przez GOTOB do bloku z oznaczeniem ETYKIETA1. Warunek sprawdza, czy zliczona głębokość pod parametrem R105 jest mniejsza od promienia pręta.

$\mathrm{R} 105=0$

ETYKIETA1:

G91 G1 Z-2

G1 Y=-_UR_SREDNICA-2*(\$TC_DP6[\$P_TOOLNO, \$P_TOOL]+1) F=_UR_R103

G1 Z-2

G1 Y=_UR_SREDNICA+2* $($ \$TC_DP6[\$P_TOOLNO, \$P_TOOL $]+1)$

$\mathrm{R} 105=\overline{\mathrm{R}} 105+4$

STOPRE

IF $\mathrm{R} 105<0.5 *$ ( UR SREDNICA+2) GOTOB ETYKIETA1

G0 Z = UR_SREDNICA+30.

ENDIF

Aby uniknąć kolizji ze względu na wysięg narzędzia oraz przekroczenie limitu w osi Z, odcięcie obrabianego przedmiotu jest frezowane do połowy półfabrykatu i przez pozycjonowanie kątowe drugiego wrzeciona pręt jest obracany o 180 stopni. Następnie powtarzana jest opisana wcześniej procedura przecinania.

SYNCON ;SPOS[2]=180;SYNCOF

W przypadku zdefiniowania parametru _UR_MOM jako równego lub większego od wartości 30 wykonuje się opisaną dalej procedurę. Działanie tego fragmentu programu jest analogiczne do poprzedniego, z tą różnicą, że podany jest skuteczny moment zacisku.

ELSE

G153 G1 AX $[X G R]=$ UR_VAR $1+$ UR ZAC F= UR FFF FXS $[X G R]=1$ FXST $[X G R]=$ UR $\_$MOM ZACISK=\$AA_FXS[XGR]

STOPRE

IF ZACISK $==1$

G153 G1 G90 XGR=0 FXS[XGR $]=0$

MSG("PRZECIW WRZECIONO NIE MOGLO DOJECHAC NA ZAPROGRAMOWANA POZYCJE") 


\author{
$\mathrm{MO}$;GOTOF PEND \\ ENDIF \\ M547 \\ GOTOB PRZECINANIE \\ ENDIF \\ M17 ;PEND: M30
}

\title{
4. Podsumowanie
}

Przedstawiony podprogram pod nazwą CYCLEV1, zapisany jako cykl użytkownika, umożliwia nową procedurę odcięcia przedmiotu, w zależności od wyboru narzędzia do tego przeznaczonego, np. przecinakiem lub frezem. Do opracowania takiego cyklu wykorzystano zmienne systemowe oraz zdefiniowane przez producenta parametry, do których są przypisane wartości zlokalizowane w GUD8 (Globalne Dane Użytkownika). Przy niewielkiej modyfikacji podprogram ten może być wykorzystany do innych obrabiarek o zbliżonej kinematyce.

\section{Literatura}

[1] Instrukcja obsługi dla MC726/MC731/MC734 z magazynem prętów Siemens 840 D. Nr dokumentacji: SM-840D-PL Wersja 2005.12 ED051209 V2.2 PL. Tłumaczenie przez MDT Sp. z o.o., Warszawa.

[2] Instrukcja obsługi MC 3xx/7xx/8xx Siemens 840 D, ED101216_POL V2.0 NIR, thumaczenie przez MDT Sp. z o.o., Warszawa.

[3] Programming Instructions, TURNING OPERATIONS MC7xx/MT. SIEMENS. Doc. No. MC726-731- 734-M/MT-840D-DEU.

[4] SIEMENS, Sinumerik 840D/840Di/810D instrukcja programowania - CYKLE. Wydanie 03.04.

[5] Stryczek R., Pytlak B.: Elastyczne programowanie obrabiarek, PWN, Warszawa 2011.

[6] www.kfilipowicz.zut.edu.pl/Programowanie/Lista\%20instrukcji\%20i\%20kodow \%20G.pdf.

[7] www.schroeder-produktionstechnik.de.

\section{PROGRAMMING THE CAPTURE CYCLE OF A WORKPIECE WITH CUT-OFF FOR THE MACHINING CENTRE}

\section{S u m m a r y}

This article shows the capture cycle with cut-off for the STAMA MC 726 MT machining centre using the SIEMENS SINUMERIK 840D system developed at the Department of Manufacturing Techniques and Automation at the Rzeszow University of Technology. The usage of created cycle allows for machining the workpiece in two clamping positions. Further, it simplifies editing the control program and reduces its size. The first chapter shows the kinematics of CNC machine control axes with their nomenclature and a range of motion on which the cycle was implemented. 
In the second chapter, the functions and operating modes provided by the machine maker that support machining programming and special global variables defined to facilitate generation of NC code were discussed. The next part presents the division of the cycle in the SINUMERIK control system and shows how created cycle works. Besides the standard codes, local, global and system variables were used to create jump conditions.

Keywords: high-level programming, parametric programming, SINUMERIK 840D, multi-axis machine

DOI: $10.7862 / \mathrm{rm} .2017 .25$

Otrzymano/received:12.07.2017

Zaakceptowano/accepted: 24.09.2017 
